ARTIGOS

\title{
FORMAÇÃO DOCENTE PARA AS RELAÇÕES ÉTNICO-RACIAIS: O QUE DIZEM PROFESSORES DE SOCIOLOGIA DO ENSINO MÉDIO?
}

\author{
Isabela RODRIGUES LIGEIRO \\ Universidade do Estado de Minas Gerais - UEMG \\ Belo Horizonte, Minas Gerais - Brasil \\ belaligeiro@gmail.com \\ José Eustáquio de BRITO \\ Universidade do Estado de Minas Gerais - UEMG \\ Belo Horizonte, Minas Gerais - Brasil \\ joseeustaquio.brito@gmail.com
}

RESUMO: Este artigo apresenta resultados de uma pesquisa de mestrado em educação, realizada entre 2018 e 2019, que objetivou compreender como aulas e atividades propostas por professores de sociologia do ensino médio têm contribuído para o desenvolvimento de uma educação das relações étnico-raciais tendo em vista a implementação da Lei 10639/03. O tema da formação docente e relações étnico-raciais se fez presente de forma recorrente na pesquisa. Este artigo aborda implicações dessa lei para formação docente considerando as diretrizes que orientam essa formação. Foram entrevistados 7 (sete) professores de sociologia do ensino médio em atividade na capital mineira e Região Metropolitana de Belo Horizonte. Os dados da pesquisa revelam que, não obstante a obrigatoriedade do ensino de história da África e cultura afro-brasileira, a formação inicial vivenciada pelos sujeitos da pesquisa não contempla, de forma satisfatória, a abordagem do tema.

PALAVRAS-CHAVE: Formação docente, ensino de sociologia, educação das relações étnico-raciais. 


\title{
TEACHING TRAINING FOR ETHNIC-RACIAL RELATIONSHIPS: WHAT DO HIGH SCHOOL SOCIOLOGY TEACHERS SAY?
}

\begin{abstract}
This article presents the results of a master's research in education, carried out between 2018 and 2019, which aimed to understand how classes and activities proposed by high school sociology professors have contributed to the development of an education in ethnic-racial relations with a view to implementation of Law 10639/03. The theme of teacher education and ethnic-racial relations was recurrently present in the research. This article addresses the implications of this law for teacher training considering the guidelines that guide this training. Seven (7) high school sociology teachers working in the capital of Minas Gerais and the Metropolitan Region of Belo Horizonte were interviewed. The research data reveal that, despite the mandatory teaching of African history and Afro-Brazilian culture, the initial training experienced by the research subjects does not satisfactorily address the theme.
\end{abstract}

KEYWORDS: Teacher training, sociology teaching, education of ethnic-racial relations.

\section{FORMACIÓN DOCENTE PARA LAS RELACIONES ÉTNICO-RACIALES: ¿QUÉ DICEN LOS PROFESORES DE SOCIOLOGÍA DE BACHILLERATO?}

RESUMEN: Este artículo presenta los resultados de una investigación de maestría en educación, realizada entre 2018 y 2019, que tuvo como objetivo comprender cómo las clases y actividades propuestas por los profesores de sociología de secundaria han contribuido al desarrollo de una educación en relaciones étnico-raciales con miras a implementación de la Ley 10639/03. El tema de la formación del profesorado y las relaciones étnico-raciales estuvo presente de forma recurrente en la investigación. Este artículo aborda las implicaciones de esta ley para la formación docente considerando los lineamientos que orientan esta formación. Se entrevistó a siete (7) profesores de sociología de secundaria que trabajan en la capital de Minas Gerais y la Región Metropolitana de Belo Horizonte. Los datos de la investigación revelan que, a pesar de la enseñanza obligatoria de la historia africana y la cultura afrobrasileña, la formación inicial de los sujetos de investigación no aborda satisfactoriamente el tema.

PALABRAS-CLAVE: Formación docente. Enseñanza de la sociología. Educación de las relaciones étnico-raciales. 


\section{INTRODUÇÃO}

Neste artigo são apresentados resultados de pesquisa desenvolvida no Programa de Mestrado em Educação, da Universidade do Estado de Minas Gerais, que objetivou compreender como as práticas pedagógicas de professores de sociologia do ensino médio estão contribuindo para uma educação das relações étnico-raciais. Além disso, a pesquisa abordou o tema da formação docente para uma educação das relações étnico-raciais e como tal formação tem repercutido nas práticas pedagógicas dos professores. Dentre as categorias demarcadas na pesquisa, este artigo reflete sobre a formação inicial universitária, compreendendo que diversas são as influências e experiências que contribuem para a proposição de conteúdos em referência ao tema.

Em 9 de janeiro de 2003, a Lei número 10.639 foi aprovada, alterando a Lei de Diretrizes e Bases da Educação Nacional ao inserir a obrigatoriedade do ensino de história da África e cultura afro-brasileira nas etapas e modalidades da educação básica. Posteriormente, essa lei é complementada pelo Parecer CNE/CP $n^{\circ}$ 003/2004 e pela Resolução CNE/CP n 001/2004, visando explicitar um conjunto de possibilidades para o desenvolvimento de conteúdos curriculares relacionados ao tema. Ao refletir sobre o sentido histórico da implementação dessa lei, Nilma Gomes (2012) afirma que a Lei 10639/03 sinaliza para uma mudança estrutural, que se propõe a construir uma educação antirracista em nosso país.

No entanto, a implementação desse projeto político e pedagógico enfrenta desafios históricos, dados pela concepção eurocêntrica subjacente aos conhecimentos acadêmicos e que orienta os currículos escolares sustentados na cultura e história europeia, do colonizador, invisibilizando e subalternizando a história e cultura dos povos colonizados. Maíra Pires Andrade (2018) pontua que é fundamental compreender o currículo brasileiro a partir dessa concepção colonial, que para ela "torna legítimo para o ensino somente a cultura do colonizador, que é branca, masculina, heterossexual e cristã, trazendo à tona no espaço escolar as discriminações, exclusões e o racismo" (ANDRADE 2018, p. 243). A autora reforça como esses mecanismos de poder, expressos na colonialidade1, permanecem nos espaços escolares ainda hoje e se manifesta, dentre outras formas, a partir de práticas racistas.

As consequências do racismo no cotidiano escolar para a vida de crianças e jovens negros são perversas, induzindo à auto rejeição, combinada à dificuldade de se sentirem pertencentes à identidade negra. Além disso, fomenta a baixa autoestima, uma vez que sua beleza quase nunca é reconhecida, bem como sua capacidade pessoal não é valorizada. No cotidiano escolar, esses sujeitos deparam-se com manifestações de racismo recreativo2 (MOREIRA, 2019), o que pode acentuar a tendência à evasão.

Dessa forma, o enfrentamento ao racismo e a efetivação da lei 10639/03 perpassam a construção de práticas pedagógicas que contemplem os processos identitários do povo negro, conferindo visibilidade à história dos afro-brasileiros e africanos e que promovam uma educação antirracista. No decorrer da pesquisa, questões referentes à formação inicial de professores de sociologia apresentaram-se como um desafio a ser enfrentado no cotidiano das interações com alunos do ensino médio de escolas públicas.

A abordagem desse tema encontra-se presente neste artigo organizado em três momentos. Tem-se como ponto de partida a reflexão acerca da centralidade da formação docente para o desenvolvimento de práticas pedagógicas antirracistas pautadas no reconhecimento da diversidade étnico-racial como um valor a ser cultivado. Em seguida, apresenta-se uma análise acerca da inserção da educação das relações étnico-raciais nas normas que orientam a formação docente em nosso país. A explicitação de dados da pesquisa referentes ao tema da formação inicial a partir das narrativas dos sujeitos entrevistados encontra-se presente na 
terceira parte do artigo. Ao reconhecerem os limites da formação universitária recebida em torno do tema, os professores de sociologia refletem sobre suas estratégias para o desenvolvimento de práticas pedagógicas comprometidas com uma perspectiva antirracista e emancipatória.

\section{Formação docente como variável-chave para o desenvolvimento da educação das relações étnico-raciais}

O reconhecimento de que a escola pública é um espaço para o qual converge uma diversidade de sujeitos é uma premissa necessária para o desenvolvimento de práticas pedagógicas capazes de criticar a cultura hegemônica, pautada em valores da colonialidade, para afirmar dimensões emancipatórias presentes nas trajetórias desses sujeitos. Nesse sentido, assim como apontou Paulo Freire, bell hooks também afirma a necessidade de se pensar as práticas dos professores no intuito de transgredir os sistemas de dominação existentes (2017). O poder hegemônico estruturante das escolas de educação básica reproduz a lógica eurocêntrica, branca e colonial do saber. A transformação dessas práticas requer, além de outros fatores, uma formação docente inicial que aborde questões inerentes às desigualdades raciais presentes em nossa sociedade.

Gomes (2012) considera que descolonizar os currículos e as práticas é um desafio para a escola e para o campo da formação dos professores, pois há o imperativo de estabelecer relações com a realidade social vivida pelos sujeitos da educação básica. Nessa perspectiva, é fundamental reforçar a necessidade das instituições escolares se reconhecerem como espaço plural, repensarem seus projetos político-pedagógicos de modo a incluir os diversos sujeitos que fazem parte desse espaço, e que toda a comunidade escolar tenha condições de refletir sobre as relações raciais na escola. Para que isso se efetive, a compreensão de que mudanças devem ocorrer é fundamental, visando a reorientação das práticas. hooks defende que,

Para que o esforço de respeitar e honrar a realidade social e a experiência de grupos não brancos possa se refletir num processo pedagógico, nós, como professores - em todos os níveis, do fundamental à universidade-, temos de reconhecer que nosso estilo de ensino tem de mudar (HOOKS, 2017, p. 51).

Essa mudança é essencial para a superação do racismo na escola. Como Kabengele Munanga aponta, não discutir a diversidade cultural existente na escola mantém o quadro de preconceito e impede muitas vezes que os alunos negros permaneçam na escola. Munanga afirma que

Não precisamos ser profetas para compreender que o preconceito incutido na cabeça do professor e sua incapacidade em lidar profissionalmente com a diversidade, somando-se ao conteúdo preconceituoso dos livros e materiais didáticos e às relações preconceituosas entre alunos de diferentes ascendências étnico-raciais, sociais e outras, desestimulam o aluno negro e prejudicam seu aprendizado (MUNANGA, 1999, p.14).

Tanto professores quanto alunos estão inseridos em uma sociedade estruturalmente racista3 e que manifesta a colonialidade sob as mais diversas formas. Concordando com Munanga (1999), a educação pode contribuir para que os jovens e adultos questionem e desconstruam os mitos de superioridade e inferioridade entre grupos humanos, divisões introjetadas pela cultura racista. Essa desconstrução implica na transformação das instituições, da estrutura social, como também das mentalidades dos docentes, que enquanto educadores poderão contribuir para uma ruptura no processo de negação da pluralidade cultural da sociedade brasileira. 
A produção acadêmica sobre formação de professores tem tematizado discussões sobre a educação das relações étnico-raciais, conforme apontado em pesquisas que nos oferecem um balanço dessa produção4. O Estado da Arte sobre formação de professores e relações étnico-raciais, que analisou as produções em teses, dissertações e artigos sobre essa temática entre os anos de 2003 e 2014 apresenta alguns elementos importantes sobre a literatura dessa temática. De acordo com Wilma Coelho, a maior incidência de publicização de discussões sobre formação de professores e relações étnico-raciais ocorreu no ano de 2013, em virtude da proximidade dos 10 anos da promulgação da Lei n. 10.639/03. Segundo a autora, as categorias mais recorrentes nos trabalhos foram: concepções, discursos e representações; rupturas com a prática; contribuições da formação e fragilidades no percurso formativo. No contexto de implementação da lei, as pesquisas que buscavam analisar estratégias de formação para a sua implementação se intensificaram. "As recomendações acerca da produção de outros sentidos relacionados à questão racial partem da compreensão da relevância destes na construção identitária de crianças e jovens que se encontram inseridos na escola" (BORGES, 2007 apud COELHO, 2018, p. 111). Esse estado da arte reconhece que o ponto convergente entre todas as produções analisadas é a defesa enfática de uma formação inicial e continuada que congregue o tema de modo sistemático.

Esses estudos sintetizam as principais questões debatidas em torno da relação entre formação docente e questão étnico-racial, revelando que é preciso aprofundar essa discussão. Assim como Gomes e Silva apontaram em 2002, essa lacuna ainda persiste:

O que assistimos, hoje, é o reconhecimento, dentro de alguns segmentos do campo educacional, da grande lacuna que a não-inclusão da diversidade cultural na formação dos professores/as e no currículo escolar tem acarretado à educação brasileira, principalmente à escola pública. (GOMES e SILVA, 2002, p. 14)

Articular a formação de professores com a temática étnico-racial aponta para formulação, nos cursos de licenciatura, de novos métodos e práticas pedagógicas, para produção e visibilização de conhecimentos afro-brasileiros e desconstrução do saber informado pela colonialidade e, principalmente, para um processo de configuração do profissional da educação com uma perspectiva antirracista. Por conseguinte, entende-se que,

Mais do que criar novos métodos e técnicas para se trabalhar com as diferenças é preciso, antes, que os educadores e as educadoras reconheçam a diferença enquanto tal, compreendam-na à luz da história e das relações sociais, culturais e políticas da sociedade brasileira, respeitem-na e proponham estratégias e políticas de ações afirmativas que se coloquem radicalmente contra toda e qualquer forma de discriminação. (GOMES e SILVA, 2002, p. 19)

Esses desafios remetem a mudanças internas e reconfiguração das ações dos docentes, seja na universidade ou na escola de educação básica. As mudanças almejadas são fundamentais na luta por uma educação libertadora, como afirma hooks:

Todos nós, na academia e na cultura como um todo, somos chamados a renovar nossa mente para transformar as instituições educacionais - e a sociedade- de tal modo que nossa maneira de viver, ensinar e trabalhar possa refletir nossa alegria diante da diversidade cultural, nossa paixão pela justiça e nosso amor pela liberdade (HOOKS, 2017, p. 50).

Sendo assim, entende-se que um curso de licenciatura que incorpore essa discussão contribuirá para que esses futuros professores construam práticas pedagógicas antirracistas capazes de refletir sobre as questões 
raciais de nosso país, e tenham conhecimentos fundamentados para fazer essa discussão na sala de aula ao enfrentamento do racismo em nossa sociedade.

\section{Educação das relações étnico-raciais nas diretrizes para a formação docente}

A Lei 10.639/03 é um marco legal e político na luta por uma educação que combata os preconceitos raciais e que fomente de forma positiva a história e cultura afro-brasileira e africana nas escolas. Nesse sentido, a legislação reconhece iniciativas que visam a promover a educação das relações étnico-raciais, bem como mobiliza o desenvolvimento de ações coletivas no âmbito dos sistemas de ensino. Dessa forma, incide sobre as diretrizes para formação de professores.

Podemos identificar esse desdobramento ao compararmos as Diretrizes Curriculares Nacionais para a Formação de Professores da Educação Básica de 2002, portanto, anteriores à Lei 10639/03, com as de 2015, posteriores à lei, e as atualmente vigentes num contexto de um governo contrário a políticas de ações afirmativas.

A Resolução CNE/CP 1, DE 18 de fevereiro de 2002 instituiu as Diretrizes Curriculares Nacionais (DCN) para a Formação de Professores da Educação Básica, em nível superior, curso de licenciatura, de graduação plena. Essas diretrizes foram publicadas após a aprovação da Lei de Diretrizes e Bases da Educação Nacional - Lei 9.394, de 1996. As Diretrizes Curriculares Nacionais para formação de professores de 2002 apresentaram pouco avanço no debate étnico-racial. A única menção a essa temática está no artigo $2^{\circ}$, que de forma superficial refere-se ao acolhimento e trato da diversidade.

Art. $2^{\circ} \mathrm{A}$ organização curricular de cada instituição observará, além do disposto nos artigos 12 e 13 da Lei 9.394, de 20 de dezembro de 1996, outras formas de orientação inerentes à formação para a atividade docente, entre as quais o preparo para:

(...)

II - o acolhimento e o trato da diversidade;

(BRASIL, MEC, 2002)

Após doze anos de vigência da Lei 10639/03, o Conselho Nacional de Educação definiu as novas DCN para formação de professores, ao aprovar a Resolução $n^{\circ} 2$, de $1^{\circ}$ de julho de 2015 . Essa resolução assume princípios das políticas de ações afirmativas implementadas durante os governos liderados pelo Partido dos Trabalhadores. Diferentemente da resolução de 2002, a resolução de 2015 apresenta diversos elementos que tratam da temática étnico-racial. Nas considerações preliminares para definição das diretrizes, a temática se faz presente, ao apontar que a diversidade étnico-racial constitui um dos princípios vitais para a melhoria e democratização da gestão e do ensino.

No Art. $3^{\circ}$, parágrafo quinto, são apresentados os princípios da Formação de Profissionais do Magistério da Educação Básica, dentre eles destaca-se o inciso segundo:

II - a formação dos profissionais do magistério (formadores e estudantes) como compromisso com projeto social, político e ético que contribua para a consolidação de uma nação soberana, democrática, justa, inclusiva e que promova a emancipação dos indivíduos e grupos sociais, atenta ao reconhecimento e à valorização da diversidade e, portanto, contrária a toda forma de discriminação; (BRASIL, MEC, 2015). (Grifo nosso).

No parágrafo sexto desse artigo são elencados elementos que devem constar no projeto de formação docente. O inciso sexto contempla a diversidade étnico-racial ao reconhecer "as questões socioambientais, éticas, 
estéticas e relativas à diversidade étnico-racial, de gênero, sexual, religiosa, de faixa geracional e sociocultural como princípios de equidade" (BRASIL, MEC, 2015). O parágrafo sétimo do artigo terceiro ainda define que:

Os cursos de formação inicial e continuada de profissionais do magistério da educação básica para a educação escolar indígena, a educação escolar do campo e a educação escolar quilombola devem reconhecer que:

I - a formação inicial e continuada de profissionais do magistério para a educação básica da educação escolar indígena, nos termos desta Resolução, deverá considerar as normas e o ordenamento jurídico próprios, com ensino intercultural e bilíngue, visando à valorização plena das culturas dos povos indígenas e à afirmação e manutenção de sua diversidade étnica;

II - a formação inicial e continuada de profissionais do magistério para a educação básica da educação escolar do campo e da educação escolar quilombola, nos termos desta Resolução, deverá considerar a diversidade étnico-cultural de cada comunidade. (BRASIL, MEC, 2015). (Grifo nosso).

O documento destaca que a base comum é pautada por uma concepção de educação emancipatória e que a formação docente necessita ter uma articulação entre teoria e prática que conduza o futuro professor "à consolidação da educação inclusiva através do respeito às diferenças, reconhecendo e valorizando a diversidade étnico-racial, de gênero, sexual, religiosa, de faixa geracional, entre outras;" (BRASIL, MEC, 2015). No Art. $8^{\circ}$ enumeram-se as aptidões que os egressos dos cursos de cursos de formação inicial em nível superior deverão desenvolver, dentre elas:

VII - identificar questões e problemas socioculturais e educacionais, com postura investigativa, integrativa e propositiva em face de realidades complexas, a fim de contribuir para a superação de exclusões sociais, étnico-raciais, econômicas, culturais, religiosas, políticas, de gênero, sexuais e outras;

VIII - demonstrar consciência da diversidade, respeitando as diferenças de natureza ambiental-ecológica, étnico-racial, de gêneros, de faixas geracionais, de classes sociais, religiosas, de necessidades especiais, de diversidade sexual, entre outras; (BRASIL, MEC, 2015). (Grifo nosso).

Por fim destacam-se no artigo décimo terceiro, parágrafo segundo, alguns conteúdos que devem estar presentes nos cursos de formação:

Os cursos de formação deverão garantir nos currículos., conteúdos específicos da respectiva área de conhecimento ou interdisciplinares, seus fundamentos e metodologias, bem como conteúdos relacionados aos fundamentos da educação, formação na área de políticas públicas e gestão da educação, seus fundamentos e metodologias, direitos humanos, diversidades étnico-racial, de gênero, sexual, religiosa, de faixa geracional, Língua Brasileira de Sinais (Libras), educação especial e direitos educacionais de adolescentes e jovens em cumprimento de medidas socioeducativas (BRASIL, MEC, 2015). (Grifo nosso).

Fica evidente, portanto, que a Lei 10639/03 incidiu positivamente no desenvolvimento das diretrizes para formação de professores posteriores à sua aprovação. No entanto, podemos constatar que as novas diretrizes para formação de professores aprovadas em 2019 apontam um retrocesso em relação às diretrizes anteriores no que tange à educação das relações étnico-raciais. 
A Resolução CNE/CP N² 2, de 20 de dezembro 2019, define as Diretrizes Curriculares Nacionais para a Formação Inicial de Professores para a Educação Básica e institui a Base Nacional Comum para a Formação Inicial de Professores da Educação Básica (BNC-Formação), sendo necessária essa alteração após a aprovação da nova Base Nacional Comum Curricular (BNCC). Essa resolução poderia instituir elementos para adequação à nova BNCC e manter os avanços da resolução de 2015. Entretanto, constata-se a retirada de considerações sobre os princípios para formação docente, bem como suprimem-se algumas elaborações e resumem-se outras. Assim, identificamos poucos artigos e incisos que abordam o tema das relações étnico-raciais.

No artigo quarto, dentre as competências específicas que os professores precisam adquirir nos cursos de formação inicial, postula-se "atentar nas diferentes formas de violência física e simbólica, bem como nas discriminações étnico-raciais praticadas nas escolas e nos ambientes digitais, além de promover o uso ético, seguro e responsável das tecnologias digitais" (BRASIL, MEC, 2019). (Grifo nosso).

No artigo sétimo instituem-se os princípios norteadores dos cursos de formação inicial, constando em seu inciso décimo quarto, a "adoção de uma perspectiva intercultural de valorização da história, da cultura e das artes nacionais, bem como das contribuições das etnias que constituem a nacionalidade brasileira" (BRASIL, MEC, 2019). (Grifo nosso).

Por fim, no artigo oitavo, a resolução define que os cursos de formação docente devem ter como fundamentos pedagógicos, dentre outros,

VIII - compromisso com a educação integral dos professores em formação, visando à constituição de conhecimentos, de competências, de habilidades, de valores e de formas de conduta que respeitem e valorizem a diversidade, os direitos humanos, a democracia e a pluralidade de ideias e de concepções pedagógicas; (BRASIL, MEC, 2019). (Grifo nosso).

Assim como a Lei 10639/03, as diretrizes curriculares nacionais para formação de professores da educação básica são um marco legal importante na implementação de uma educação das relações étnico-raciais. Verificar os retrocessos na resolução de 2019 exige que comunidade escolar e entidades do movimento negro mantenham centralidade na luta por uma educação antirracista, pois compreendemos que a educação não está desvinculada das movimentações da sociedade. Dessa forma, considera-se que formação docente é variável chave para o desenvolvimento da educação das relações étnico-raciais, pois, como afirmado pelo movimento negro, "enquanto houver racismo, não haverá democracia"5.

\section{A formação docente a partir das trajetórias acadêmicas dos professores de sociologia}

Consideramos que uma prática pedagógica antirracista se fundamenta em uma formação inicial que assuma em seu currículo o debate das relações étnico-raciais. Entretanto, a formação de professores tem se esquivado desse assunto, formando, em sua maioria, docentes sem acúmulo teórico sobre a história e cultura afro-brasileira e africana. Com isso, tem-se que a atuação do professor sobre essa temática ainda parte em grande medida de mobilizações individuais, por empatia, por reconhecimento em seu próprio corpo, por achar que esse assunto é importante para a formação dos alunos. Essa percepção se fundamenta no perfil de nossos entrevistados, bem como em suas narrativas a esse respeito.

Em seguida apresentamos um quadro com perfil dos entrevistados citados no artigo para evidenciar os sujeitos com os quais dialogamos no trabalho. 


\begin{tabular}{ccccccc}
\hline 1- Nome & 2-Cor & $\begin{array}{c}\text { 3- } \\
\text { Graduação: }\end{array}$ & $\begin{array}{c}\text { 4-IES } \\
\text { onde } \\
\text { formou }\end{array}$ & $\begin{array}{c}\text { 5-Ano } \\
\text { em que } \\
\text { formou }\end{array}$ & $\begin{array}{c}\text { 6- Você } \\
\text { conhece a Lei } \\
\text { 10.639/03? }\end{array}$ & $\begin{array}{c}\text { 7-Conhecimento } \\
\text { sobre a lei veio da } \\
\text { graduação? }\end{array}$ \\
\hline Angenor & Branco & $\begin{array}{c}\text { Ciências } \\
\text { Sociais }\end{array}$ & UFMG & 2012 & Sim & Não \\
\hline Milton & Preto & $\begin{array}{c}\text { Ciências } \\
\text { Sociais }\end{array}$ & UFMG & 2017 & Sim & Não \\
\hline Marielle & Branca & $\begin{array}{c}\text { Ciências } \\
\text { Sociais }\end{array}$ & UFMG & 2015 & Sim & Não \\
\hline Lélia & Preta & $\begin{array}{c}\text { Ciências } \\
\text { Sociais }\end{array}$ & $\begin{array}{c}\text { U.F. de } \\
\text { Rondônia }\end{array}$ & 2013 & Sim & Não \\
\hline Carolina & Branca & $\begin{array}{c}\text { Ciências } \\
\text { Sociais }\end{array}$ & UFMG & 2010 & Não & Não \\
\hline Luiz & Pardo & $\begin{array}{c}\text { Ciências } \\
\text { Sociais }\end{array}$ & UFJF & 1999 & Sim & Não \\
\hline Francisco & Branco & $\begin{array}{c}\text { Ciências } \\
\text { Sociais }\end{array}$ & UFMG & 2015 & Sim & Não \\
\hline
\end{tabular}

Gomes (2010), ao destacar que a atuação individual do professor ainda é a forma mais comum pela qual se dá a aplicação da lei, afirma que professores exercem tais práticas por escolhas subjetivas, não em razão do conhecimento sobre a lei. A autora reconhece que:

O desencadeamento desse processo não significa o seu completo enraizamento na prática das escolas da educação básica, na educação superior e nos processos de formação inicial e continuada de professores (as). [...] A Lei 10.639/03 e suas diretrizes precisam ser compreendidas dentro do complexo campo das relações raciais brasileiras sobre o qual incidem. Isso significa ir além da adoção de programas e projetos específicos voltados para a diversidade étnico-racial realizados de forma aleatória e descontínua (GOMES, 2010, p. 08).

A partir das interações realizadas com os sujeitos da pesquisa, configurou-se um quadro que explicita pontos de referência distintos para o desenvolvimento de práticas pedagógicas voltadas à abordagem das relações étnico-raciais em escolas de ensino médio da região pesquisada.

Ao abordar o tema, o professor Francisco6 aponta que discute a temática a partir da realidade que ele encontrou dentro da escola, com a quantidade de alunos negros e negras. Ele afirma que conheceu a Lei 10639/03 em virtude de seu interesse pessoal sobre a questão racial, não em função de uma orientação da escola para discutir esse tema, tampouco teve alguma formação na universidade sobre essa lei. Pontua que o Conteúdo Básico Comum (CBC) de sociologia traz a questão de raça, mas que o documento não faz menção a essa lei. Oliveira (2016) considera que o ensino de Sociologia tem condições privilegiadas para o desenvolvimento de práticas pedagógicas que debatam as questões raciais, que desnaturalizam e combatam o racismo, que reflitam sobre a história e cultura afro-brasileira e africana. Francisco ainda reforça sobre a lei:

Eu também vejo poucas vezes alguém tratando sobre ela, o que a gente vê muito comum é a caça aos negros no final do ano. Na consciência negra, vamos trazer um negro para falar da questão da negritude, principalmente professores de história envolvidos nisso, mas fora isso não vejo ninguém tocar nessa lei. 
A percepção da realidade da docente Marielle a impele a discutir sobre raça e racismo. Para ela, não tem como ser um bom professor ou um bom cientista social que não veja a desigualdade como um fator central no país, que não é natural. Ela também admite que não teve formação sobre o tema na faculdade. Com isso, acredita que a iniciativa de debater esses assuntos possa ter vindo de seu desenvolvimento político, pois já foi integrante de um partido político. Para tratar o tema de forma crítica, preconiza a necessidade de se ter "uma sensibilidade cientifica, se é que existe isso, mas tem que ter o afeto também, para perceber e sentir que isso é um problema, para ver a estrutura da sociedade brasileira e ver isso como um problema". Sobre a lei, obteve o conhecimento através de seu relacionamento com um professor de história.

Gomes (2012), considera que a implementação da Lei 10639/03 contribui para que o jovem negro, por meio das práticas empregadas pelos professores, afirme a sua identidade negra, bem como reconheça a história e lutas do povo negro de nosso país. Apontamento que reforça a necessidade de uma formação inicial que debata essas questões, para que tal prática seja antirracista.

Por ser homem negro, o professor Milton entende que "é necessário debater essa temática porque essa é, também, a minha realidade, é meu corpo presente na sala de aula, um corpo que vive no Brasil racista". Discorre sobre como não teve acesso a essas discussões na sua época de escola e considera que talvez, se tivesse tido, poderia ter acumulado e feito questionamentos que só foi formular já mais velho, depois de ingressar na faculdade. Ele também não teve formação teórica específica sobre o tema durante a formação em ciências sociais. Seu conhecimento sobre a Lei 10639/03 é recente, data de 2016, e informa que ele veio da internet, não foi do curso de licenciatura.

O racismo se faz presente na vida dos professores e professoras, tal violência, em alguma medida, também mobiliza os docentes a discutir, mesmo não tendo tido formação acadêmica para tal, essa questão em sala de aula.

Gomes e Laborne apontam que:

O racismo é violento e produz violência. Uma violência que incide sobre determinados sujeitos, portadores de sinais diacríticos específicos, frutos de uma ancestralidade negra e africana. No imaginário sociorracial, aos portadores desses sinais soma-se tudo de negativo que a violência racista construiu no contexto das relações de poder, na luta de classes, na desigualdade de gênero e sexual (GOMES e LABORNE, 2018, p. 215).

Diante disso, a professora Lélia, mulher negra, percebe a necessidade de debater e enfrentar o racismo a partir de sua vivência. Desde a juventude participou de conselhos juvenis, do grêmio estudantil, de militância política, de um curso da área de ciências humanas. Por já ter sofrido racismo, considera que isso a mobiliza para debater tais questões.

As experiências de vida também são fundamentais para o docente Angenor pensar suas aulas. Ele diz de sua sensibilidade, por ser homem gay e ter vivenciado preconceitos na escola, e ter tomado consciência disso mais tarde. Angenor relata que frequentou algumas conversas, na internet, que tem vivências fora da academia que foram sensibilizando-o e capacitando para debater o tema em sala de aula. Nunca teve formação na universidade sobre o tema e que conhece a lei por iniciativa própria.

O interesse de escutar os jovens é o que motiva a professora Carolina. A mesma acredita que ouvir sobre a realidade deles é essencial, pois eles têm mais condições de falar sobre racismo do que ela, que é branca. 
Ela comenta que pode "apresentar dados, estatísticas, teorias sociológicas, mas eles, os alunos, sabem mais o que é o racismo no Brasil por vivenciarem na pele, e que a partir das aulas eles se sentem confortáveis para falar". A docente não conhecia a Lei 10639/03.

O educador Luiz tem militância social, ativismo em movimentos comunitários, no movimento estudantil, no movimento político partidário. Então, entende que toda essa carga de pró-atividade própria dos movimentos sociais contribui para o seu processo pedagógico e para a construção de aulas que enfrentem as desigualdades.

Ao analisar os dados da pesquisa acerca da formação inicial, defrontamo-nos com um desafio para a implementação das diretrizes da Lei 10639/03. A falta de formação e informação dos professores a respeito da lei e de literatura sobre a temática étnico-racial dificulta a implementação de uma educação antirracista. Nenhum dos entrevistados, todos formados em universidades federais, tiveram formação sobre essa lei e suas implicações na graduação. Isso é um reflexo de como nossas universidades ainda são elitizadas e reproduzem o racismo institucional e estrutural. 


\section{Conclusão}

Em 2009, Gomes coordenou uma pesquisa de alcance nacional com o objetivo de mapear iniciativas que estavam implementando as Diretrizes Curriculares para Educação das Relações Étnico-Raciais. A pesquisa apontou diversas considerações, dentre elas que essas ações ainda são resultado de iniciativas individuais e isoladas de professores/as interessados/as, geralmente negros/as, em trabalhar pedagogicamente a questão racial dentro das escolas7. Passada mais de uma década de realização dessa pesquisa, a nossa investigação também evidenciou que a formação inicial na graduação tem sido percebida como insuficiente para a abordagem da educação das relações étnico-raciais, e que os professores atuam principalmente de forma isolada. Além disso, observou-se que a atuação na perspectiva da lei também depende do interesse do professor, pois de acordo com os entrevistados, nenhum teve formação sobre a lei e suas diretrizes. Portanto, a prática desses professores advém de suas inciativas, seja por ter empatia com a causa, seja por serem negros, seja por envolvimento com movimentos sociais e partidos políticos. Em nenhum caso eles relataram ter tido uma formação inicial que os impulsionasse a discutir tais questões.

Outro aspecto identificado na pesquisa, diz respeito ao fato de que os professores, mesmo os que têm conhecimento da Lei 10639/03, não trabalham a temática étnico-racial em sala de aula em função da lei, evidenciando um conhecimento superficial sobre uma legislação tão importante para a educação, consequência de uma formação inicial que ainda legitima o racismo estrutural e institucional do Brasil. É incompreensível que cursos de licenciatura em ciência sociais, ministrados em uma universidade federal, não tenham disciplinas obrigatórias sobre a história e cultura afro-brasileira e africana, nem discutam as legislações que impulsionam uma educação justa e democrática, com respeito à igualdade racial em nosso país.

Por mais que já tenham se passado 17 anos da aprovação da lei, é necessário que a luta pela implementação de suas diretrizes seja permanente; que as universidades que ainda não introduziram o debate sobre a implementação da lei na formação inicial de professores da educação básica o façam; que os governos criem as condições materiais para o trabalho de fortalecimento desse campo, como garantir uma formação continuada na perspectiva da Lei 10639/03; que os docentes tenham incentivos aos estudos e pesquisas sobre a temática e as escolas tenham orientações permanentes sobre como implementar as diretrizes da lei; que haja acompanhamento periódico dos sistemas de ensino para verificação e mapeamento das práticas quanto à abordagem das questões étnico-raciais, que os professores sejam responsáveis por buscar conhecimentos que subsidiem a prática dos princípios que norteiam uma educação antirracista e planejem suas ações de forma a garantir o enfrentamento ao racismo, bem como o debate sobre os diversos conhecimentos a respeito da África e da cultura Afro-brasileira.

Entendemos que ainda existem grandes desafios para uma educação antirracista e para o enfrentamento ao racismo na sociedade brasileira, mas que eles não são impossíveis de serem superados, como percebemos nos relatos das aulas dos professores entrevistados, na luta e resistência permanente do povo negro e na defesa constante de uma educação antirracista e democrática. 


\section{Endnotes}

1 De acordo com Walter Mignolo, a “colonialidade” é um conceito que foi introduzido pelo sociólogo peruano Anibal Quijano, no final dos anos 1980 e no início dos anos 1990. A colonialidade nomeia a lógica subjacente da fundação e do desdobramento da civilização ocidental desde o Renascimento até hoje, da qual colonialismos históricos têm sido uma dimensão constituinte, embora minimizada. Cf. Mignolo, 2017.

2 Segundo Adilson Moreira (2019), racismo recreativo se refere a uma política cultural que utiliza o humor para hostilizar as características físicas ou culturais dos grupos raciais estabelecidos como inferiores. Apontadas como brincadeiras ou piadas tratam-se de ações veladas de racismo.

3 A expressão "racismo estrutural" faz alusão ao fato de ser o racismo uma decorrência da estrutura da sociedade que normaliza e concebe como verdade padrões e regras baseadas em princípios discriminatórios de raça. De acordo com Sílvio Almeida (2019), o racismo é parte de um processo social, histórico e político que elabora mecanismos para que pessoas ou grupos sejam discriminados de maneira sistemática.

4 O dossiê temático "Educação e relações étnico-raciais: o estado da arte”, publicado pelo periódico Educação em Revista (2018), apresenta um artigo que discute o tema sob a perspectiva da formação docente.

5 Título da matéria publicada em 01 de julho de 2020 pelo jornal Le monde diplomatique Brasil, de autoria de Wania Sant’Anna e Maria José Menezes. Disponível em https://diplomatique.org.br/enquanto-houver-racismo-nao-havera-democracia/.

6 As referências aos professores de sociologia entrevistados preservam o anonimato de suas identidades, de acordo com o prescrito no termo de consentimento livre e esclarecido assinado pelos sujeitos da pesquisa.

7 Trata-se da pesquisa intitulada "Práticas pedagógicas de trabalho com relações étnico-raciais na escola na perspectiva da Lei no $10.639 / 03$ ", patrocinada pela Unesco e editada em livro pelo Ministério da Educação no ano de 2012. Disponível em http://ciclopermanenteufmg.com.br/wp-content/ uploads/2018/07/Pr\%C3\%A1 ticas-Pedag\%C3\%B3gicas-de-Trabalho-com-a-Lei-10.639_03.pdf. 


\section{REFERÊNCIAS}

ALMEIDA, Sílvio. Racismo estrutural. São Paulo: Suely Carneiro; Pólen, 2019.

ANDRADE, Maíra Pires. A branquitude e a colonialidade na prática docente na educação básica (2000-2015). Revista da ABPN • v. 10, Ed. Especial - Caderno Temático: História e Cultura Africana e Afrobrasileira - lei 10.639/03 na escola. Goiânia, maio de 2018, p. 238-264.

BRASIL. Conselho Nacional de Educação. Resolução CNE/CP n 2, de 20 de dezembro de 2019. Define as Diretrizes Curriculares Nacionais para a Formação Inicial de Professores para a Educação Básica e institui a Base Nacional Comum para a Formação Inicial de Professores da Educação Básica (BNC-Formação). 2019.

BRASIL. Conselho Nacional de Educação. Resolução CNE/CP n. 02/2015, de $1^{\circ}$ de julho de 2015. Define as Diretrizes Curriculares Nacionais para a formação inicial em nível superior (cursos de licenciatura, cursos de formação pedagógica para graduados e cursos de segunda licenciatura) e para a formação continuada. Brasília, Diário Oficial [da] República Federativa do Brasil, seção 1, n. 124, p. 8-12, 02 de julho de 2015.

BRASIL. MEC/SECAD. Educação anti-racista : caminhos abertos pela lei federal № 10.639/03. Secretaria de Educação Continuada, Alfabetização e Diversidade. Brasília. 2005. 236 p. (Coleção Educação para todos).

BRASIL. MEC. Lei no 10.639, de 9 de janeiro de 2003. Altera a Lei no 9.394, de 20 de dezembro de 1996, que estabelece as diretrizes e bases da educação nacional, para incluir no currículo oficial da Rede de Ensino a obrigatoriedade da temática «História e Cultura Afro-Brasileira», e dá outras providências. 2003.

BRASIL. Conselho Nacional de Educação. Resolução cne/cp 1, de 18 de fevereiro de 2002. Institui Diretrizes Curriculares Nacionais para a Formação de Professores da Educação Básica, em nível superior, curso de licenciatura, de graduação plena. 2002.

COELHO, Wilma de Nazaré Baía. Formação de professores e relações étnico-raciais (2003-2014): produção em teses, dissertações e artigos. Educ. rev. Curitiba, v. 34, n. 69, p. 97-122, jun. 2018. Disponível em <http:// www.scielo.br/scielo.php?script=sci_arttext\&pid=S0104-40602018000300097\&lng=pt\&nrm=iso $>$. https:// doi.org/10.1590/0104-4060.57233

GOMES, Nilma Lino. Relações étnico-raciais, educação e descolonização dos currículos. Currículo sem Fronteiras, v.12, n.1, pp. 98-109, Jan/Abr 2012.

GOMES, Nila Lino. Diversidade étnico-racial como direito à educação: a Lei n 10.639/03 no contexto das lutas políticas da população negra no Brasil. Belo Horizonte: XV Encontro Nacional de Didática e Prática de Ensino, ENDIPE, 2010(no prelo). 2010.

GOMES, Nilma Lino; LABORNE, Ana Amélia de Paula. Pedagogia da crueldade: racismo e extermínio da juventude negra. Educação em Revista |Belo Horizonte|v.34|e197406|2018.

GONÇALVES e SILVA, Petronilha Beatriz; BARBOSA, Lúcia Maria de Assunção (Orgs.). O Pensamento Negro em Educação no Brasil: expressões do movimento negro. São Carlos, SP: EdUFSCar, 1997. 
HOOKS, Bell. Ensinando a transgredir: a educação como prática da liberdade. São Paulo: Martins Fontes, 2017.

MIGNOLO, Walter D. Colonialidade; o lado mais escuro da modernidade. Rev. bras. Ci. Soc., São Paulo, v. 32, n. 94, e329402, 2017. Disponível em <http://www.scielo.br/scielo.php?script=sci_arttext\&pid=S0102$-69092017000200507 \&$ lng=pt\&nrm=iso. https://doi.org/10.17666/329402/2017.

MOREIRA, Adilson. Racismo recreativo. São Paulo: Editora Jandaíra, 2019.

MUNANGA, Kabengele (Org.). Apresentação Superando o racismo na escola. [Brasília]: Ministério da Educação, Secretaria de Educação Continuada, Alfabetização e Diversidade, 1999. 204p.

OLIVEIRA, Luiz Fernandes de. Uma Sociologia para quem e para quê? Relações raciais no livro didático de Sociologia. In: COELHO, Wilma de Nazaré B; MÛLLER, Tânia M. P.; SILVA, Carlos A. F. da. (Org.). Formação de Professores, Livro Didático e Escola Básica. São Paulo: Editora Livraria da Física, 2016, v. 1, p. 129-154

LIGEIRO, I. R.; BRITO, J. E.; Formação docente PARA as relações étnico-raciais: o que dizem professores de sociologia do ensino médio? Formação Docente - Revista Brasileira de Pesquisa sobre Formação de Professores. Belo Horizonte. Vol. 13, n. 27 (p. 11-26) 31 ago. 2021. ISSN: 2176-4360. DOI https://doi.org/10.31639/rbpfp.v13i27.476 
